\title{
THE INTRAMENINGEAL TREATMENT OF TABES AND CEREBROSPINAL SYPHILIS *
}

\author{
THOMAS R. BOGGS, M.D., AND R. R. SNOWDEN, M.D. \\ BALTIMORE
}

The treatment of syphilis of the central nervous system has always been unsatisfactory. The cerebrospinal system is a closed one, and the diffusion of drugs from the circulating blood into the cerebrospinal fluid is slow and incomplete. For this reason organisms which have invaded the nervous tissue or meninges remain more or less protected from the drugs which may be present in the vascular system. For a number of years the desirability of the direct application of antisyphilitic drugs has been recognized. Horsley ${ }^{1}$ went so far as to advocate the "heroic" treatment of opening into the subdural space and washing out with mercuric chlorid $(1: 1,000)$ solution, but this procedure proved too irritating.

With the advent of salvarsan and neosalvarsan, hope was entertained that this therapeutic agent could be injected intraspinally; but investigation showed that it also damaged the tissues. Wechselmann ${ }^{2}$ found that small amounts ( $1 \mathrm{mg}$.) when injected into the brains of dogs and rabbits at a concentration of $1: 500$ and $1: 1,000$ produced convulsions, weakness of the limbs and death in from two to fourteen days; but small doses, from 0.5 to $0.25 \mathrm{mg}$., in greater dilution (from 1:2,000 to $1: 4,000)$ caused no reaction. Later he reported ${ }^{3}$ the intraspinous injection of neosalvarsan in four patients without reaction, giving each from $0.5 \mathrm{mg}$. to $3 \mathrm{mg}$. Marinesco ${ }^{4}$ reports thirteen cases in which neosalvarsan was given intraspinally, the dose averaging about $5 \mathrm{mg}$. In two patients no reaction occurred, but in the remainder the reaction was severe; thus, eight patients developed incontinence of urine or retention, three showed weakness of the extremities and in one case anesthesia of the rectum, legs and buttocks occurred. Ellis and Swift ${ }^{5}$ have carefully studied the effects of the intraspinous injection of salvarsan and neosalvarsan in monkeys. They injected small quantities and considered the cell-count as an indication of reaction due to irritation.

* Submitted for publication Dec. 30, 1913.

* From the Medical Clinic of the City Hospital at Bay View.

1. Horsley, V.: Neurol. Centralbl., 1910, xxiv, 257.

2. Wechselmann, W.: Die Behandlung des Syphilis mit Dioxydiamidoarsenobenzol, "Ehrlich-Hata 606," Berlin, 1911, p. 11.

3. Wechselmann, W.: Deutsch. med. Wchnschr., 1912, xxxviii, 1446.

4. Marinesco: Diatet. u. physik. Therap., 1913, xvii, 194.

5. Swift and Ellis: Jour. Exper. Med., 1913, xviii, 428. 
They found that the intraspinal injection of even minute quantities (0.2 mg.) produced profound cellular reactions which persisted over ten days, while $3.2 \mathrm{mg}$. caused, in one monkey, paralysis of the hind legs, which lasted several months. The injections of neosalvarsan were, on the whole, less severe, but still gave evidence of irritation in doses as small as $0.045 \mathrm{mg}$. Repeating the injection seemed to increase these effects.

The study of the effects of the intravenous or intramuscular injection of salvarsan brought to light a very important fact. Plaut ${ }^{6}$ showed that the serum of patients who have received salvarsan exerts a definite antisyphilitic effect, whereas normal serum has no such activity, and the serum of patients treated with iodids and mercury has very little such power. Meirowsky and Hartman ${ }^{7}$ and Gibbs and Calthrop ${ }^{8}$ treated cases of syphilis with good results by injecting subcutaneously serum taken from other patients who had received salvarsan. In the same way Henry Alsten ${ }^{9}$ successfully treated several cases of frambesia. Ellis and Swift ${ }^{10}$ took up the study of this serum and showed that, when taken from the patient within six hours after the salvarsan injection, it inhibits the growth of the Treponema pallidum, but if taken before treatment, or from six to twenty-four hours after treatment, there is no inhibition. They also reported beneficial effects from the intraspinal injection of this serum, with very few irritative phenomena.

This spirochetacidal activity of salvarsanized serum was further studied by Gonder, ${ }^{11}$ Castelli, ${ }^{12}$ and Ellis and Swift, ${ }^{13}$ who showed by the use of animals that it had a marked effect on the virulence of several spirochetes, and that this effect was demonstrable only by the injection into animals of the organisms so treated. Thus, Swift and Ellis ${ }^{13}$ showed that the serum of rabbits treated intravenously with salvarsan, and the serum of patients treated likewise with salvarsan or neosalvarsan exerted an inhibitory effect on the Spirochaeta duttoni; and that these spirochetes did not appear objectively (dark field) changed, but they would not cause infection in animals into which they were injected. These investigators also found that heating the serum at $56 \mathrm{C}$. $(132.8 \mathrm{~F}$.) for half an hour markedly increased the activity of the serum, and that this increase is due only in part to the destruction of some inhibiting sub-

6. Plaut: Deutsch. med. Wchnschr., 1910, xxxvi, 2237.

7. Meirowsky and Hartman: Med. Klin., 1910, vi, 1572.

8. Gibbs and Calthrop: British Med. Jour., 1911, i, 809.

9. Alsten, Henry: British Med. Jour., 1911, i, 360.

10. Swift and Ellis: New York Med. Jour., 1912, xevi, 53-55.

11. Gonder, R.: Ztschr. f. Immunitätsforseh., Orig., 1912, xv, 57.

12. Castelli, G.: Ztschr. f. Chemotherap., Orig., 1912, i, 122 and 167.

13. Swift and Ellis: Jour. Exper. Med., 1913, xviii, 435. 
stance. They also showed that the cerebrospinal fluid does not possess these inhibitory bodies.

The intraspinal injection of serum, taken an hour after the intravenous administration of salvarsan, was first employed by Swift and Ellis as a method of treating cerebrospinal syphilis. Their technic ${ }^{14}$ was, in brief, the following: One hour after the intravenous injection of salvarsan 40 c.c. of blood are withdrawn directly into a bottle-shaped centrifuge tube, and allowed to coagulate, after which it is centrifugalized. The following day 12 c.c. of this serum are pipetted off and. diluted with 18 c.c. of normal saline solution. This 40 per cent. solution is then heated at $56 \mathrm{C}$. for half an hour. By lumbar puncture the cerebrospinal fluid is withdrawn until the pressure is reduced to $30 \mathrm{~mm}$. (water), after which enough of the serum solution is run in by gravity exactly to replace the cerebrospinal fluid withdrawn.

During the past year and a half the cases of cerebrospinal syphilis in the City Hospital at Bay View have been treated along the lines laid down by Ellis and Swift, with one important change-we injected undiluted serum in large quantities (25-35̃ c.c.). Thus, there was given, in many instances, twice as much actual serum at a single injection as was given by Ellis and Swift. The technic was the following: Salvarsan, $0.6 \mathrm{gm}$., was given intravenously, having been made up in water distilled within an hour of time of using, and the solution was injected at once. One hour later from 75 to 100 c.c. of blood were withdrawn into a large, sterile tube, and this was set aside to clot. After from one to eighteen hours the serum was pipetted off and centrifugalized at high speed for fifteen minutes in order to throw down any red blood-corpuscles present. The serum was then heated in a water-bath at $56 \mathrm{C}$. for half an hour and the intraspinal injection made at once. A lumbar puncture was done and the spinal fluid was slowly and carefully drained off into a graduated sterile cylinder. Not more than 35 c.c. were removed. The serum was then injected, a syringe and two-way stop-cock being used, the serum being drawn back into the syringe from the flask and then slowly injected through the needle. Great care was taken not to use any undue pressure in running in the serum. Enough was injected to replace exactly the amount of spinal fluid removed, whether this was only a few cubic centimeters or as much as 35 c.c. After the injection all pillows were removed, the foot of the bed elevated and the patient kept on his back in this position for at least an hour. The treatments were repeated at intervals of seven to twenty days, when possible, depending in part on the way in which the patient reacted.

The brief protocols of eight unselected cases are appended as illustrative of the method, with note of some of the difficulties and dangers,

14. Swift and Ellis: Tre Archives Ivt. Med., 1913, xii, 331. 
and the results achieved. Some cases are still under treatment at the time of this report.

\section{REPORT OF CASES}

Case 1.-An unmarried colored laundress, aged 37 , was admitted suffering from tertiary syphilis with cerebrospinal infection and syphilitic cerebral thrombosis.

History.-The primary infection occurred twenty years before onset of present illness. No secondaries showed but tertiary lesions appeared during the past five years. The patient had had slight, irregular mercurial treatment during past five years. Severe frontal headacles had existed for a week before admission, with the development of flaceid, left-side paralysis, which came on suddenly eighteen hours before admission with no loss of conseiousness or convulsions.

Examination.-Complete left-side paralysis, which included the muscles of the face, arm and leg, with moderately exaggerated deep reflexes and positive Babinski's sign. Neck stiff and retracted. Several large, luetic ulcerations over lower abdomen.

Treatment and Result.-After admission the patient was given three injections of salvarsan and two intraspinal injections. In the first treatment blood was withdrawn seventy-two hours after the injection, and in the second twenty-four hours after injection. When discharged the patient was normal physically except for a slight residual paralysis of the flexors of the left forearm and a left pes equinus. On admission the cerebrospinal fluid showed twenty cells per cubic millimeter; when discharged there were seven cells per cubic millimeter. Wassermann was positive on admission, negative when patient was discharged.

CASE 2.-A married, white window-washer aged 44, was admitted ill with tabes dorsalis.

History.-Primary infection had occurred twenty years before admission. The present illness began five years before admission with sharp, shooting pains in the legs. Extreme ataxia had developed in past two years. The patient had had six weeks' treatment in a German army hospital at the time of primary chancre. About two months later he was given another short course of iodids and mercury.

Examination.-No sphincter disturbances. Argyll Robertson pupils present, knee-jerks absent, muscle sense in legs much impaired, marked ataxia, causing great difficulty in walking.

Treatment and Result.-Two intravenous injections of salvarsan and two intraspinal injections were given with consequent improvement. On admission the patient was very ataxic and suffering severely with lightning pains. After the second treatment the lightning pains had ceased entirely and he could walk much better. He felt so much improved that he refused to remain for further treatments.

CASE 3.-An unmarried white man, a clerk, aged 37, on admission was found to be aftlicted with tabes dorsalis.

History.-The primary infection had occurred nine years prior to admission and seven years before onset of present illness, wnich was accompanied with lightning pains, gradually increasing unsteadiness in walking and dimness of vision. Bladder symptoms developed about a year after onset. At the time of the primary chancre the patient had local treatment and took pills by mouth for one month; during the past eighteen months, mercury and iodids continuously. One year ago he was given an intramuscular injection of salvarsan and a second three months later.

Examination.-Argyll Robertson pupils. General enlargement of lymph-nodes. Knee-jerks absent, muscle sense completely absent in the legs, moderate dulling of tactile and pain sense. Romberg sign markedly positive. Positive Wassermann in blood-serum and spinal fluid and ten cells per cubic millimeter in spinal fluid. 
Treatment and Result.-Four intravenous injections of salvarsan, three of neosalvarsan, and six intraspinal injections were given. Total: salvarsan 2.7 gm., serum 116 c.c.; time, seventy-nine days. On admission the patient was unable to walk on account of the ataxia. At present he walks fairly well without assistance. He is now free from the lightning pains. The cells in the spinal fluid dropped from ten to six per cubic millimeter, and Wassermann reaction has changed from complete tixation to a very faint fixation. The reactions were very severe, prostrating the patient, and for this reason the treatments were discontinued.

CAse 4.-An unmarried, white salesman, aged 37, was admitted with cerebrospinal syphilis and syphilitic lateral sclerosis.

History.-The primary infection was incurred fifteen years before onset of present illness two and a half years ago, when unsteadiness in walking developed, soon followed by weakness and stiffness of the legs. Paresthesias, numbness, girdle sensations and bladder symptoms deveioped within eighteen months. The patient has had several short mercurial courses by mouth and by inunction.

Examination.-General enlargement of lymph-nodes. Pupils unequal but react normally. Knee-jerks greatly exaggerated on both sides; ankle-clonus present and Babinski sign positive. Legs stiff and spastic and held in adduction. Patient walks with difficulty. Wassermann on blood-serum, 60 per cent fixation. Positive Wassermann and twenty-five cells per cubic millimeter in cerebrospinal fluid.

Treatment and Result.-Two intravenous injections of neosalvarsan, six of salvarsan and eight intraspinal injections were given; total: salvarsan, $3.9 \mathrm{gm}$., serum 178 c.c.; time, 195 days (two admissions). On admission the patient was so spastic as to be unable to stand on his feet and he was suffering severely with girdle sensations. These disappeared immediately and the spasticity became distinctly less marked until he can now walk without assistance and can go up and down stairs. In the spinal fluid the cells have fallen from twenty-five to five per cubic millimeter, and the Wassermann from complete fixation to very faint fixation.

CASE 5.-A married white man, blacksmith, aged 45, was admitted with tabes dorsalis, partial optic atrophy and tertiary syphilis.

History.-Primary infection appeared as a chancre twenty-two years before aamission. Present illness began four years before admission with dimness of vision, soon followed by lightning pains which have gradually become more and more intense. Unsteadiness in gait has developed during the past two years; no sphincter disturbances. At the time the chancre appeared a few local applications of calomel powder were made; no medicine was given internally. During the past four years the patient has had more or less continuous treatment with mercury and iodids.

Examination.-Moderate enlargement of lymph-nodes. Argyll Robertson pupils and primary optic atrophy. Inee-jerks absent; moderate ataxia of legs. Positive Wassermann and thirty-five cells per cubic millimeter in spinal fluid. Wassermann in blood-serum negative.

Treatment and Result.-Eight intravenous injections of salvarsan and eight intraspinal injections were given; total: salvarsan, $4 \mathrm{gm}$.; serum, 204 c.c.; time, 108 days. This patient had been unable to work for six months on account of the severe lightning pains. After the first treatment he was entirely free from pains except for one mild attack. The cell-count in the spinal fluid fell from thirty-five to five per cubic millimeter, and the Wassermann from positive to negative.

CASE 6.-A white man, bookkeeper, widower, aged 54, was admitted suffering from tabes dorsalis.

History.-Primary infection occurred twenty-four years prior to admission. Initial lesion was not known, possibly a chancre. Two years before admission 
the patient had an acute retention of urine, and examination at that time showed inactive pupils, knee-jerks faint, bladder atonic and anesthetic, and a positive Wassermann in spinal fluid. Eighteen months ago he began to suffer with severe pains in the back, coming on in paroxysms about every half hour, worse at night. A hemiplegia, three years ago has cleared up almost completely, the right side having been involved. The patient has had several short courses of iodids and mercury by mouth during the past two years.

Examination.-Argyll Robertson pupils. Unilateral sweating involving the whole left side of the head and neck. Slight residual weakness and exaggeration of reflexes of right arm and leg. Knee-jerk almost absent on left. Wassermann in blood-serum negative. Positive Wassermann and sixty-two cells per cubic millimeter in spinal fluid.

Treatment and Result.-Two intravenous injections of neosalvarsan, seven of salvarsan and nine intraspinal injections were given. Total: 3.9 gm., serum, 186 c.c.; time, seventy-seven days. When admitted the patient was almost prostrated on account of the severe and constant pain in the back. This steadily became less intense and the patient was quite comfortable when discharged. The cells in the spinal fluid fell from sixty-two to four per cubic millimeter and the Wassermann changed from positive to negative.

CASE 7.-An unmarried colored man, a cook, aged 45, was admitted under diagnosis of tabes dorsalis with optic atrophy.

History.-The primary infection had occurred twenty-seven years before onset of present illness, which began five years before admission, with unsteadiness and weakness of the legs; the subsequent history is typical. There has been incontinence of urine for three years. Lightning pains have been constant but not severe. Numerous gastric and laryngeal crises have occurred during the past year. The patient has had failing vision for eighteen months. For the past year the ataxia has been so severe that he has been practically helpless. The patient had a short course of local treatment at time of chancre; mercury and iodids by mouth during past year.

Examination.-Patient greatly emaciated. Complete loss of muscle sense in the arms and legs with exaggerated ataxia of the muscles of the face, arms and legs. Argyll Robertson pupils. Deep reflexes of arms and legs absent. Wassermann in blood-serum negative. Positive Wassermann and thirty-six cells per cubic millimeter in spinal fluid.

Treatment and Result.-Three intravenous injections of salvarsan and two intraspinal injections were given. Total: salvarsan, $1.2 \mathrm{gm}$.; serum, 35 c.c.; time, thirty-six days. Patient suffered an extreme reaction after the second intraspinal injection which was characterized by severe respiratory depression. Immediately after the injection, at $4 \mathrm{p}$. m., it was noticed that the patient seemed slightly dazed and did not answer questions so quickly as usual, although he was perfectly rational. Twenty minutes later the mouth began to twitch and pull to the right, the eyes turned to the right, and the right arm and leg began to jerk slightly. The respirations suddenly dropped to four a minute, and were very irregular, the sequence usually being two or three spasmodic respirations followed by a long period of apnea, sometimes lasting three-quarters of a minute. The jerking and twitching soon ceased and the patient became quite flaccid. At $6 \mathrm{p}$. $\mathrm{m}$. it became necessary to give artificial respiration for about half an hour. A lumbar puncture was done at 7 p. m., and 10 c.c. of the spinal fluid, tinged with the serum, were allowed to drop out. At 8 p. m. another puncture was done and the spinal canal washed out three times with normal saline. It was noticed that the intraspinal pressure varied with the respirations in the normal manner, and there was no noticeable change in the condition of the patient when the canal was drained or filled with 35 c.c. of normal saline. The condition of the patient remained about the same until 1 a. m., when he suddenly sat up in bed, recognized those about him and talked rationally. In about fifteen min- 
utes he again suddenly sank into apparent coma, with spasmodic and irregular respirations, four or five to the minute, and remained thus until 4 a. m., when. as before, he suddenly recovered, was perfectly rational and showed no signs of weakness. When questioned the patient asserted he was entirely conscious at all times and told with a fair degree of accuracy what was done and who was in the room. He suffered no pain, but simply could not breathe, although he felt a great desire to do so. The next day he was as well as usual. No more treatments were given and he left the hospital in a week, unimproved.

Case 8.-An unmarried white man, a painter, aged 47, was admitted suffering from cerebrospinal syphilis.

History.-The primary infection occurred twenty-six years before admission. The patient was admitted on account of acute alcoholism. When examined the eyes showed Argyll Robertson pupils. For the past year he has suffered witl pains in the back and giddiness. The patient had a short course of local treatment at time of chancre.

Examination.-Reflexes all normal, knee-jerks active. Wassermann on bloodserum negative. Faintly positive Wassermann and fifty-four cells per cubic millimeter in spinal fluid.

Treatment and Result.-Four intravenous injections of salvarsan and four intraspinal injections were given. Total: salvarsan, $2.4 \mathrm{gm}$; serum, 118 c.c.; time, thirty-six days. The cells in the spinal fluid dropped from fifty-three to ten per cubic millimeter; the Wassermann remained positive. The patient felt perfectly well and could not be induced to remain longer in the hospital.

From the foregoing cases it is evident that the intraspinal method is a step torward in the treatment of tabes and cerebrospinal syphilis. The patients were uniformly relicved from pain, and as far as locomotion is concerned there was a slow but definite improvement, in some instances amounting almost to restitution to normal. It is in this respect that our cases seemed to do better than those of Swift and Ellis, perhaps on account of the larger doses of serum.

'The psychic effect of the treatment is also marked. The patients became encouraged by the quick relief of pain and the first improvements in the control of motion and were faithful in their efforts to use the legs and practice walking, stair climbing, etc. The nutrition also rapidly improved under these stimuli. In fact, this very improvement was a hindrance in our series, for with the class of people under our care it was in most instances impossible to keep them in the hospital long enough to carry the treatment as far as we should have liked to do.

The effect of the treatment on the cerebrospinal fluid was very striking. The cell-count first fell to normal, the Wassermann reaction becoming negative some time after the cells were reduced. It has seemed from our observations that the Noguchi reaction was of little value during the carrying out of this treatment, since such large amounts of globulin were injected into the spinal canal. At any rate, the Noguchi reactions were positive, in most instances, after the cell-count and Wassermann indicated a normal fluid.

Where the patients are intelligent enough to appreciate the necessity for repetition of the treatment until the biologic indices of normal are 
maintained, there need be but transient interruptions of regular occupation, lasting forty-eight to serenty-two hours as a rule. It is also true that while the risks are minimal, they do exist and in all probability very feeble, advanced tabetics or rery acute cases of cerebrospinal lues should not be treated in this way." ${ }^{10}$

In those of our cases which were treated with the undiluted serum the reactions were sometimes more severe than those reported by Swift and Ellis-pain in the abdomen, legs and rectum, with occasional nausea and vomiting or dizziness, and in a few instances a little fever. We do not feel, however, that these constitute any contra-indication to the larger doses of whole serum, especially in the light of the apparently greater benefit to the patient. 'The reactions produced by the injection of the salvarsanized serum from another patient were very severe, as shown by two of our cases, the donors of the serum receiving an equal quantity of the same lot, at the same time and in the same way, having no reaction at all.

It is quite evident that so indirect a method of applying arsenic in the treatment of syphilis of the central nervous system cannot be considered as final; but we believe it is an advance on what has gone before and a spur to the findings of new preparations or new methods more suitable for the accomplishment of the desired results.

15. One of us has treated by this method a tabetic with diabetes mellitus. The patient was told of the risk, but wanted to take any chance. He had had five previous intravenous treatments with salvarsan. Eighteen hours after the injection of 20 c.c. of salvarsanized serum he developed diabetic coma and was very ill for five days, when a large intravenous transfusion of sodium carbonate and glucose turned the scale and he recovered from the coma. He was not benefited by the treatment except in the disappearance of the lightning pains. 